Journal of Engineering and Applied Sciences 14 (24): 9692-9700, 2019

ISSN: 1816-949X

(C) Medwell Journals, 2019

\title{
Artificial Intelligence Technique to Real-Time Based on Selective Harmonic Elimination in Modified Multilevel Inverter
}

\author{
Mohammed Rasheed, Rosli Omar, Marizan Sulaiman, Wahidah Abd Halim and \\ Moataz M.A. Alakkad Majeda \\ Faculty of Electrical Engineering (Industrial Power), Universiti Teknikal Malaysia Melaka, \\ 76100 Hang Tuah Jaya, Durian Tunggal, Melaka, Malaysia \\ rasheed@utem.edu.my
}

\begin{abstract}
In this study, Artificial Intelligence (AI) technique is applied to determine the switching angles for a uniform step asymmetrical modifiedmultilevel inverter by eliminating specified higher-order harmonics while maintaining the required fundamental voltage and current waveform. Artificial intelligence technique based on Selective Harmonic Elimination (SHE) method in a modifiedmultilevel inverter has been proposed in this study. The Selective Harmonic Elimination Pulse-Width Modulation (SHE-PWM) is a powerful technique for harmonic minimization in multilevel inverter. The proposed a five-level Modified Cascaded H-Bridge Multilevel Inverter (M-CHBMI) with Artificial Neural Network (ANN) controller to improve the output voltage and current performance and achieve a lower Total Harmonic Distortion (THD). The main aims of this study cover design, modeling, prediction for real-time generation of optimal switching angles in five level modified topology of the CHB-MLI for a single-phase. Real-time application of Selective Harmonic Elimination-Pulse Width Modulation (SHE-PWM) technique is limited due to the heavy computational cost involved in solving aspecified number of transcendental nonlinear equations known as Selective Harmonic Elimination (SHE) equations that contain trigonometric functions. Simulation of a 5-level inverter in MATLAB/Simulink reveals that the proposed method is highly efficient for harmonic reduction in modified multilevel inverter.
\end{abstract}

Key words: Harmonics, artificial intelligence, modified multilevel inverters, five level, fundamental voltage, modulation

\section{INTRODUCTION}

With the advent of fast switching semiconductor devices with high power handling capability real-time multilevel power conversion has become a rapidly growing area of power electronics with good potential for further development. In multilevel inverter can be generate AC voltage based on DC source from PV, winding and battery application. The multilevel inverter has three advantage, converted $\mathrm{DC}$ to $\mathrm{AC}$ voltage, reduce Total Harmonic Distortion (THD) and less number of switches component (Rasheed et al., 2019). In multilevel inverter have been three type of topologies clamped capacitor (DC) Flying Capacitor (FC) Cascaded H-Bridge (CHB) (Rasheed et al., 2018). The structure of multilevel inverter for consist eight switching drive can be generated five level inverters. Therefore, increase number of switching PWM leads to increase output voltage level and then leads to high cost for circuit (Omar et al., 2019). However, the multilevel inverter has limitation harmonic order in 7-level 3th, 5th by using optimization technique are PSO, NR and GA algorithms are present by Salleh et al. (2011). In nine level multilevel inverter with Phase Disposition (PD) PWM scheme can be generated waveform voltage and current based on Transistor Clamped H-Bridge multilevel inverter (TCHB) with DC supply equal $500 \mathrm{~V}$ signal frequency is $50 \mathrm{~Hz}$, modulation index and currier frequency $2000 \mathrm{~Hz}$ in this circuit done by simulation MATLAB for produce lower (THD) (Reddy et al., 2010). The harmonic elimination technique applies to multilevel inverter of seven and eleven level for elimination 3rd, 5 th and $3 \mathrm{rd}, 5$ th and 7 th, respectively have been explanation by Parkash et al. (2014). For optimization control have different type can be applied to multilevel inverter to optimized switching angle for capability of THD minimization. The optimization PSO and GA and HSA techniques have been used for computing switching angle via. solved non-liner transcendental equation drive from Selective Harmonic Elimination (SHE) for output voltage based on 7-level cascaded $\mathrm{H}$-bridge multilevel

Corresponding Author: Mohammed Rasheed, Faculty of Electrical Engineering (Industrial Power), Universiti Teknikal Malaysia Melaka, 76100 Hang Tuah Jaya, Durian Tunggal, Melaka, Malaysia rasheed@utem.edu.my 
inverter have been present by Colak and Kabalci (2013). The (SHE) considered low-frequency technique in order to elimination 3rd and 5th based on 7-level inverter with different Modulation Index (MI) equal to 0.65-1.0, the optimum harmonic reduction have been present by Xiao et al. (2012). PSO algorithm implementation for decrease THD of CHB-MLI compare five and seven level can be observe that THD for 7-level much better than 5-level inverter have been live in Subramanian and Rasheed (2013) and Demirdelen et al. (2017). According to the conventional circuit using in CHB-MLI consist eight switching PWM for produce five level inverter and then twelve switching PWM for generate seven level inverters (Bodo et al., 2012 and Hosseini et al., 2011). The iteration solved number of switching angle by non-linear equation was achieve by PSO technique. The optimization switching angle by PSO technique equal 3 angles based on 7-level inverter with reduce harmonic distortion 3rd and 5th odd has monic order. NR and PSO have been achieve by excremental and simulation result (Nedumgatt et al., 2012). For improving the quality of the output voltage inverter for two types of $\mathrm{MLI}$ as symmetrical and asymmetrical, both types are very effective and efficient for multilevel inverter utilize reduced number of switching devices with Hybrid topologies for the conventional and non-conventional multilevel inverter topologies to create a specified number of output voltage levels in operating in higher voltage levels based on DC voltage supply (Ahmed et al., 2010).

The research proposal of a five-level Modified Cascaded H-Bridge Multilevel Inverter (M-CHBMI) with Artificial Neural Network (ANN) controller has been improve the output voltage and current performance and achieve a lower Total Harmonic Distortion (THD). The ANN controller has been covered design, modeling, prediction for real-time generation of optimal switching angles in five level modified topology of the CHB-MLI for a single-phase. The study is design to simulate the 5-level M-CHBMI using MATLAB Simulink and to develop a proposed ANN controller algorithm for the 5-level CHBMI to achieve lower output voltage THD and improve the output voltage and current performance.

\section{MATERIALS AND METHODS}

\section{The modified of a CHB-MLIs}

Five-level configuration: The output voltage's of switching functions determine its harmonic components, thus, to some degree, reduction of harmonics is limited. Figure 1 shows the proposed single-phase five-level-

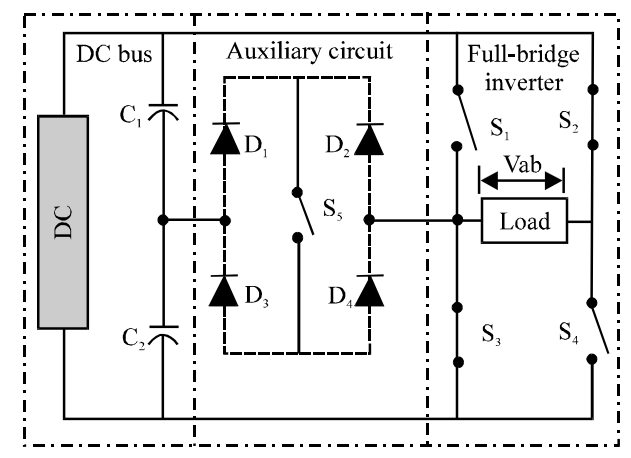

Fig. 1: Proposal modified of a CHB-MLI, single-phase five-level topology

Table 1: Output voltage for five level to the switche's on $=1$-off $=0$

\begin{tabular}{lllllll}
\multicolumn{7}{l}{ Table 1: Output voltage for five level to the switche's on $=1$-off $=0$} \\
\cline { 2 - 7 } State & $\mathrm{S}_{1}$ & $\mathrm{~S}_{2}$ & $\mathrm{~S}_{3}$ & $\mathrm{~S}_{4}$ & $\mathrm{~S}_{5}$ & $\mathrm{Vo}$ \\
\hline $\mathrm{A}$ & 1 & 0 & 0 & 1 & 0 & $\mathrm{Vdc}$ \\
$\mathrm{B}$ & 0 & 0 & 0 & 1 & 1 & $\mathrm{Vdc} / 2$ \\
$\mathrm{C}$ & 0 & 0 & 1 & 1 & 0 & 0 \\
$\mathrm{D}$ & 1 & 1 & 0 & 0 & 0 & $0^{*}$ \\
$\mathrm{E}$ & 0 & 1 & 0 & 0 & 1 & $-\mathrm{Vdc} / 2$ \\
$\mathrm{~F}$ & 0 & 1 & 1 & 0 & 0 & $-\mathrm{Vdc}$ \\
\hline “*" Significant value
\end{tabular}

inverter topology. As a solution, this work presents of switching pattern a five-level PWM inverter with output voltages zero, $+1 / 2 \mathrm{Vdc}, \mathrm{Vdc},-1 / 2 \mathrm{Vdc}$ and $-\mathrm{Vdc}$ as shown in Fig. 2 based on Table 1. Increased number of output levels reduces harmonic content. It adopts a full-bridge configuration with an auxiliary circuit comprising four diodes and a switch and generates half-level of DC bus voltage. The block diagram of a modified CHB-MLIs with SC source based on controller ANN algorithm as shown in Fig. 3 and 4.

Harmonic minimization problem: The equations for 5-levels based on the are described below (Vijaykumar et al., 2015; Rodiguez et al., 2007 and Tipsuwanporn et al., 2011):

$$
\begin{aligned}
& f(t)=f_{\theta 1}(t)+f_{\theta 2}(t) \sum_{n=1,2,5}^{\infty} \frac{2 V d c}{n \pi}\left(V_{d c 1} \cos \left(n \alpha_{1}\right)+\right. \\
& \left.V_{d c 2} \cos \left(n \alpha_{2}\right)\right) \sin (n w t)
\end{aligned}
$$

Where:

$\mathrm{Vdc}=$ Voltage of each voltage source that was in unity $\theta_{\mathrm{i}}=$ The switching angles

From Eq. 1 and 2, four equations were resulted in eliminating the 5 th harmonic:

$$
\begin{gathered}
\mathrm{V}_{\mathrm{AN}}=\mathrm{V}_{\mathrm{dc} 1} \\
\mathrm{~b}_{\mathrm{n}}=\frac{2 \mathrm{~V}_{\mathrm{dc}}}{\pi}\left\{\cos \left(\mathrm{n} \alpha_{1}\right)+\cos \left(\mathrm{n} \alpha_{2}\right)\right\} \mathrm{n}=1,3,2
\end{gathered}
$$



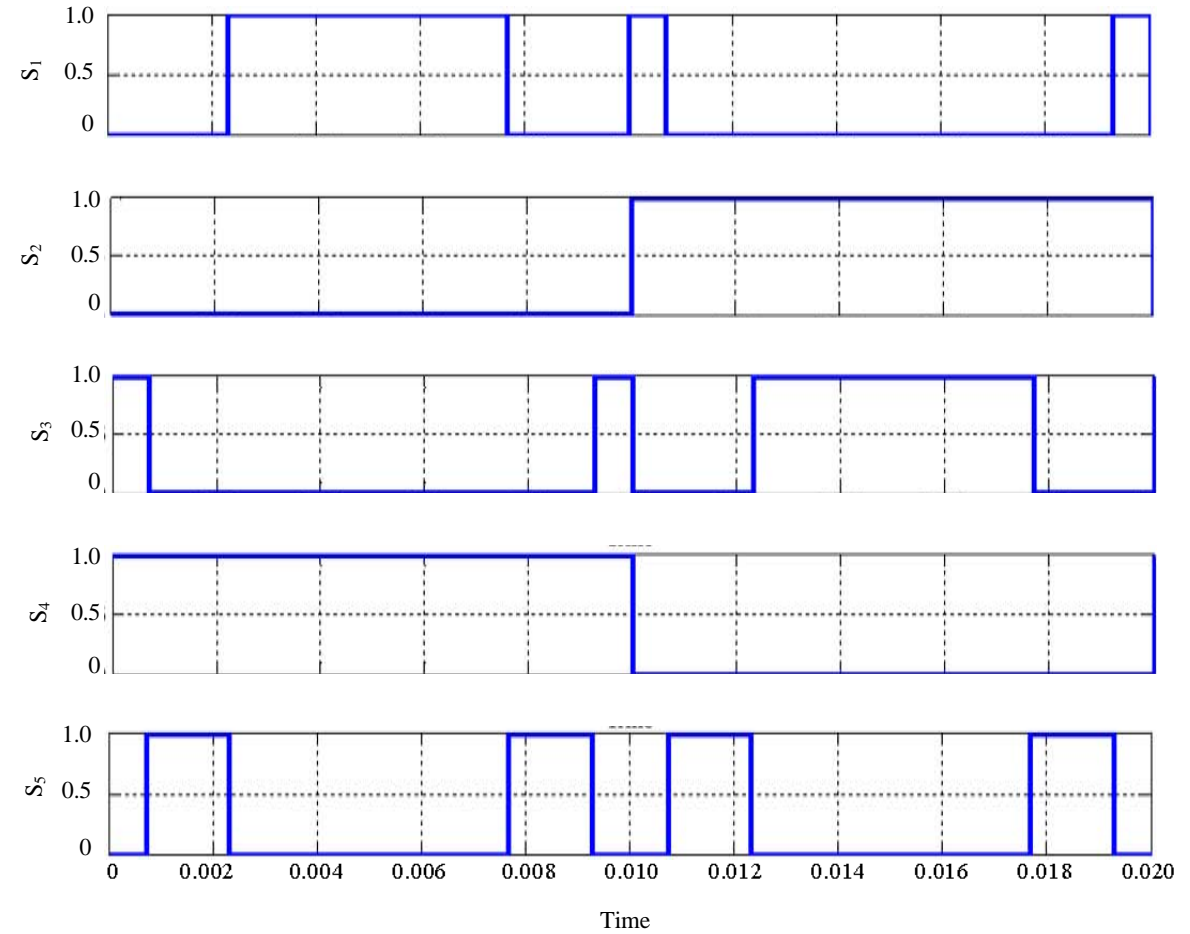

Fig. 2: Switching pattern for 5-level modified of a CHB-MLI

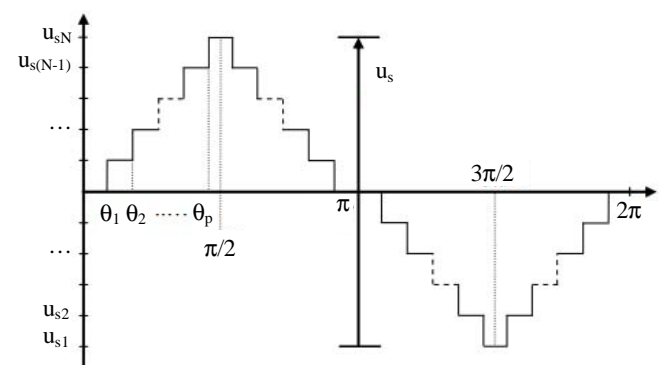

Fig. 3: Vab at low switching frequency CHB-MLIs for 5-levels

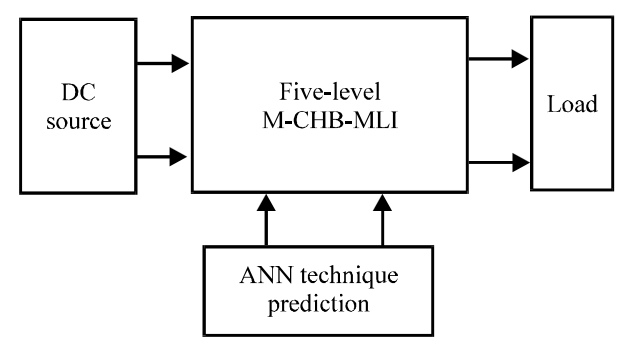

Fig. 4: Block diagram of a modified CHB-MLIs with DC source using ANN algorithm

Equation 2 has $\mathrm{s}$ variables $\left(\theta_{1}, \theta_{2}\right)$ where $0<\theta_{1}<\theta_{2}<\pi / 2$ and a solution set is obtained by assigning a specific value to the fundamental component, Vf and equating s-1 harmonics to zero as given below:

$$
\begin{aligned}
& \mathrm{V}_{1} \cos \left(\theta_{1}\right)+\mathrm{V}_{2} \cos \left(\theta_{2}\right) 2 \mathrm{~m} \\
& \mathrm{~V}_{1} \cos \left(3 \theta_{1}\right)+\mathrm{V}_{2} \cos \left(3 \theta_{2}\right)=0
\end{aligned}
$$

where, $\mathrm{m}=\mathrm{Vf} /(2 \mathrm{Vdc} / \pi)$ and it is related to the modulation index $\mathrm{mi}$ by $\mathrm{mi}=\mathrm{m} / \mathrm{sec}$ where $0<\mathrm{mi}<1$. An objective function is then needed for the optimisation procedure selected as a measure of effectiveness of eliminating selected order of harmonics while maintaining the fundamental component at a pre-specified value. Therefore, this objective function is defined as:

$$
\begin{aligned}
& \mathrm{F}\left(\theta_{1}, \theta_{2}, \ldots, \theta_{\mathrm{s}}\right)=\left[\sum_{\mathrm{n}=1}^{\mathrm{s}} \mathrm{V}_{1} \cos \left(\theta_{\mathrm{n}}\right)-\mathrm{m}\right]^{2}+ \\
& {\left[\sum_{\mathrm{n}=1}^{\mathrm{s}} \mathrm{V}_{2} \cos \left(3 \theta_{\mathrm{n}}\right)\right]^{2}+\cdot\left[\sum_{\mathrm{n}=1}^{\mathrm{s}} \mathrm{V}_{\mathrm{s}} \cos (2 \mathrm{~s}-1) \theta_{\mathrm{s}}\right]^{2}}
\end{aligned}
$$

The optimal switching angles are obtained by minimizing Eq. 4 subject to the constraint $0<\theta_{1}<\theta_{2}<\pi / 2$ and consequently the required harmonic profile is achieved. The main challenge is the non-linearity of the transcendental set of Eq. 3 as most iterative techniques can be used with five levels of the modified CHB-MLIs as shown in Fig. 4 and each step is explained below:

The values of the conducting angles $\theta_{1}, \theta_{2}$ can be chosen by solving the transcendental equations using a modulation index formula Eq. 5 to obtain the suitable: 


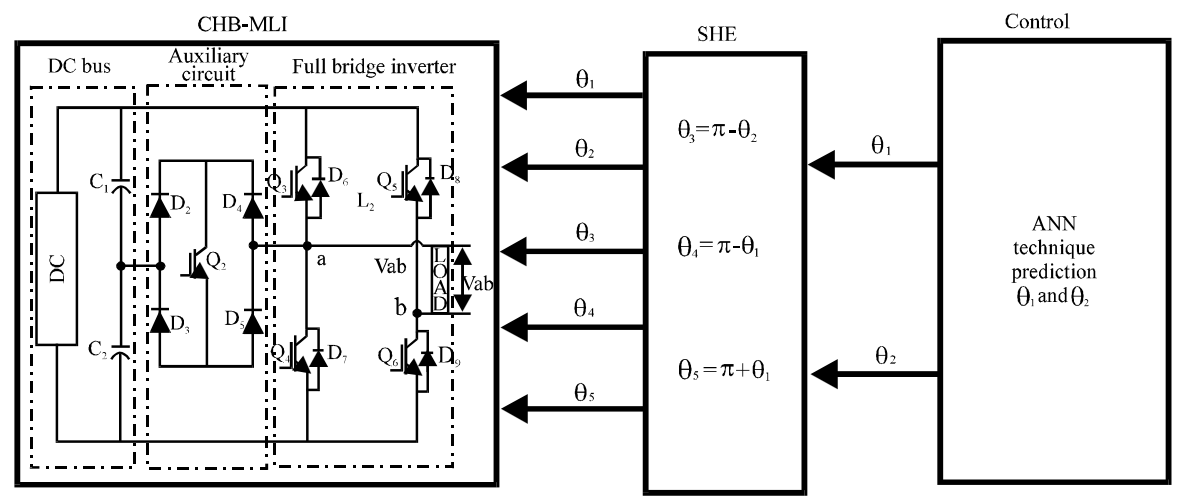

Fig. 5: Model of a single phase of modified CHB-MLIs and its controller using ANN algorithm

$$
\mathrm{M}=\frac{\pi \mathrm{Vf}}{2 \mathrm{~V}_{\mathrm{dc}}}(0 \leq \mathrm{M} \leq 1)
$$

where, modulation index values $\mathrm{m}_{\mathrm{i}}$. Other angles which are $\theta_{3}$ until $\theta_{8}$ can be obtained by referring the output waveform of 5-levels of a modified CHB-MLIs theory in Fig. 3. The procedure of detecting attributes and configuration of a system is called optimisation. For only 3 rd harmonics can be eliminated chosen to be removed. Thus, the switching angle can be found by solving transcendental equations by using ANN technique. In order to generate $\mathrm{S}_{1}, \mathrm{~S}_{2}, \mathrm{~S}_{3}, \mathrm{~S}_{8}$, for 5-levels inverter, the switching pattern as shown in Fig. 2 are turned on and off in the right sequence in order to produce 5-level output voltage waveform of a modified CHB-MLIs. These switching angles are then examined for their corresponding $\mathrm{THD}$ given by:

$$
\mathrm{THD}_{\mathrm{V}}=\frac{\sqrt{\sum_{\mathrm{n}=1}^{\infty} \mathrm{V}_{\mathrm{n}}^{2}}}{\mathrm{~V}_{1}}
$$

The effect of predicted angles for five-levels are $\alpha_{1}$ and $\alpha_{2}$, on the THD and the modulation index is shown in Fig. 3. By using MATLAB coding for number of iterations, it can be easily concluded that the modulation index equal 0.949 . However, the THD value of five-levels equal to $14.48 \%$.

Based on the diagram as shown in Fig. 1 the specified diagram has been modelled using MATLAB/Simulink. Finally, the model of a single phase of modified CHB-MLIs and its controller using ANN algorithm based on MATLAB/Simulink can be illustrated in Fig. 5.

ANN performance evaluation: ANN is a powerful tool to control an onlinear system that is very complex in nature.

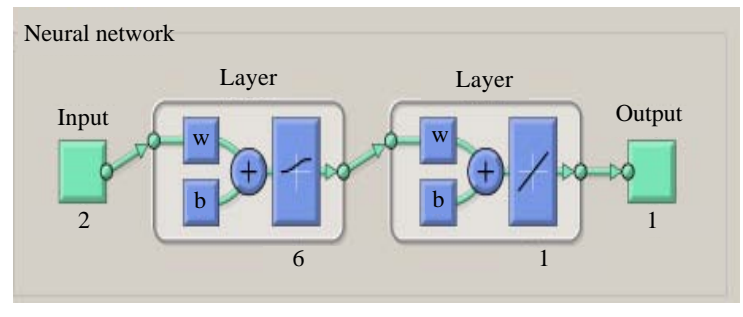

Fig. 6: ANN controller block diagram

A well-designed ANN can be used to replace the look up table and to generate optimal switching angles in a real-time manner (Zhang, 2017).

A typical two-layer feed-forward network shown in Fig. 6 with sigmoid hidden neurons and linear output neurons can fit multidimensional mapping problems arbitrarily well. There are ninputs and vectors pin an input layer, $t_{1}$ sigmoid hidden neurons in hidden layer and $t_{2}$ linear output neurons in output layer.

The ANN architecture is illustrated by Fig. 6 including an input layer with two inputs, a hidden layer with two hidden neurons and an output layer with two outputs. A Simulink Model is created using the ANN with delayed feed-back loop as shown in Fig. 7.

ANN controller network structure is defined based on the number of neurons in the input layer, hidden layer and output layer, respectively. The first neuron of the output layer is used as input to feed the PWM generator to generate switching signal for the proposed M-CHBMI.

The connections weight parameter between $\mathrm{jth}$ and ith neuron at mth layer is given by wmij, while bias parameter of this layer at ith neuron is given by bmi. Transfer function of the network at ith neuron in mth layer is defined by: 


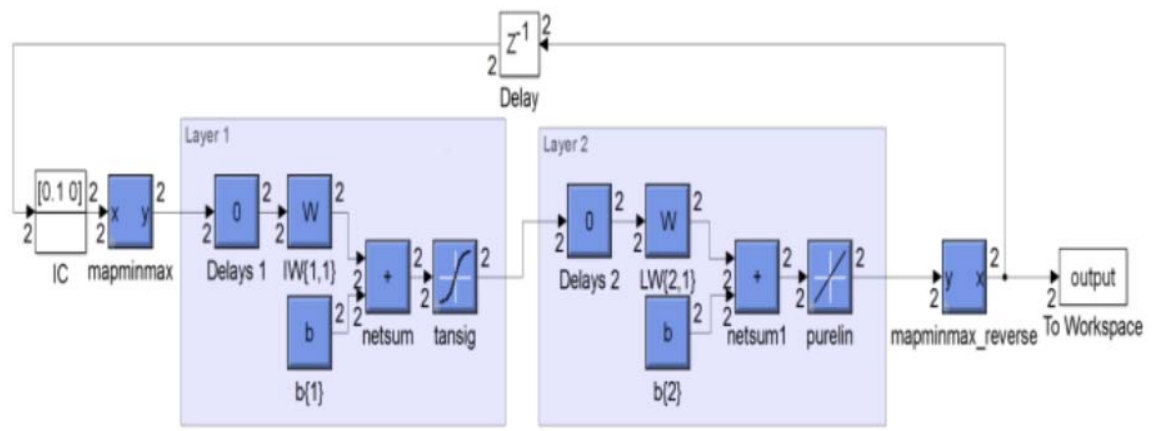

Fig. 7: Simulink Model for ANN-based Henon map chaotic system

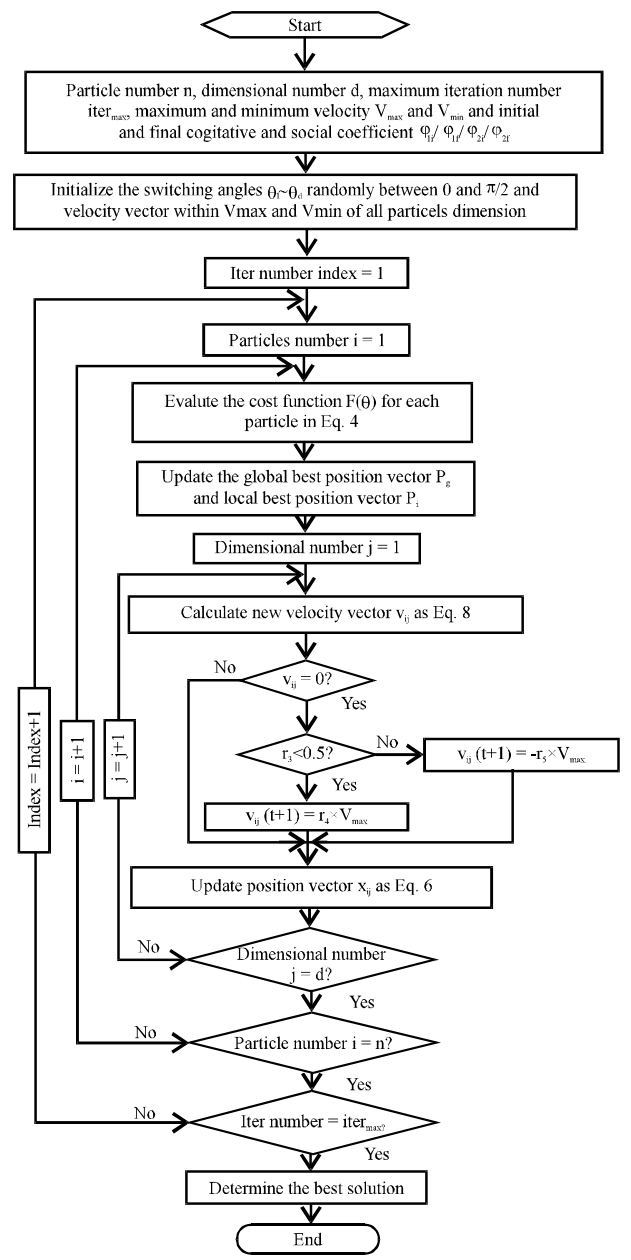

Fig. 8: Flow chart of ANN applying to harmonic minimization problem

$$
\mathrm{n}_{\mathrm{i}}^{\mathrm{m}}=\sum_{\mathrm{j}=1}^{\mathrm{S}^{\mathrm{m}-1}} \mathrm{~W}_{\mathrm{ij}}^{\mathrm{m}} \mathrm{a}_{\mathrm{j}}^{\mathrm{m}-1}+\mathrm{b}_{\mathrm{i}}^{\mathrm{m}}
$$

The output function of neuron at mth layer is given by:

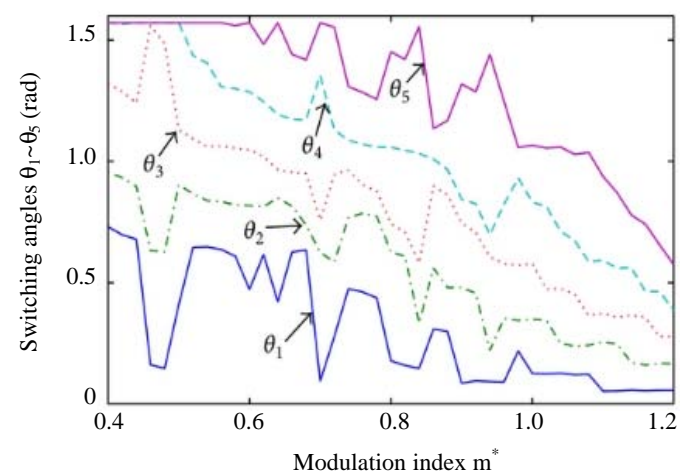

Fig. 9: Calculated switching angles $\theta_{1}$ and $\theta_{2}$

$$
\mathrm{a}_{\mathrm{i}}^{\mathrm{m}}=\mathrm{f}^{\mathrm{m}}\left(\mathrm{n}_{\mathrm{i}}^{\mathrm{m}}\right)
$$

where, $\mathrm{f}$ is activation function of the neuron. In this design the activation function of the output layer is unity and for the hidden layer is a tangent hyperbolic function given by:

$$
\mathrm{f}^{\mathrm{m}}\left(\mathrm{n}_{\mathrm{i}}^{\mathrm{m}}\right)=\frac{2}{1+\mathrm{e}^{-2 \mathrm{n}_{\mathrm{m}}^{\mathrm{m}}}}-1
$$

Appling ANN to the harmonic minimization problem described in above section, the procedure is presented in Fig. 8 and the results of optimal switching angles are presented in Fig. 9.

The training performances and training states for the three training functions of the selected architecture with 2 hidden neurons are plotted in Fig. 10a. As Fig. 10b, illustrates the mean squared error below $10^{-7}$ for gradient, for $\mathrm{Mul} 0^{-9}$ and validation 0 with 1000 iteration. Although, the overall performance is improving with increasing number of hidden neurons, it is hard to predict accurately whether the performance can be improved by adding one more neuron for an individual iteration. 


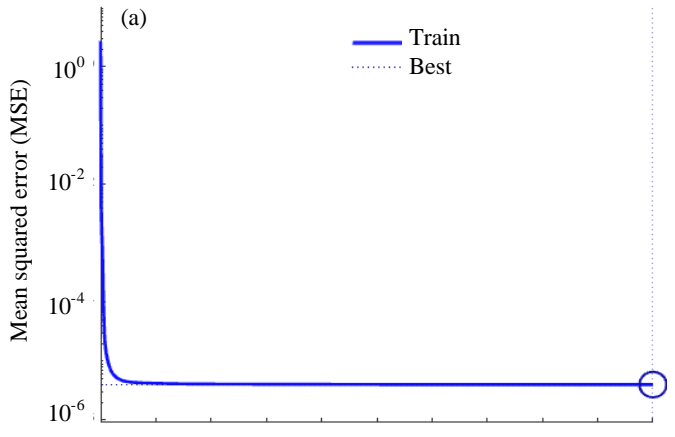

(b)
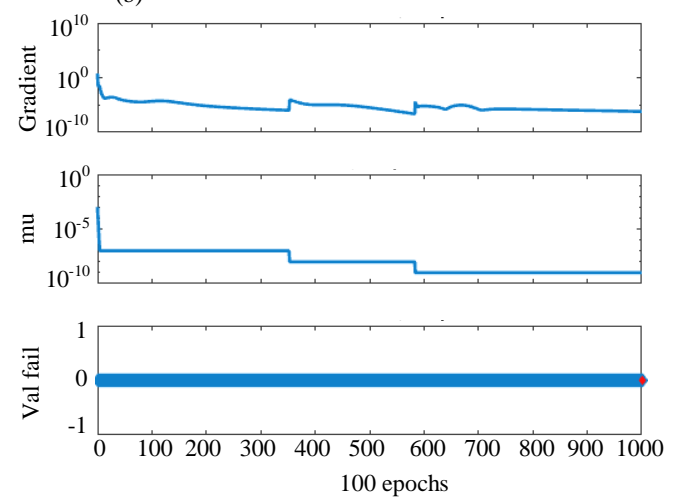

Fig. 10: ANN training performance with 2 hidden neurons. a) Best training performance is $3.9784 \mathrm{e}-06$ at epoch 1000 and b) Gradient $=$ $6.3219 \mathrm{e}-07$ at epoch $1000, \mathrm{Mu}=1 \mathrm{e}-09$ at epoch 1000 , validation checks $=0$ at epoch 1000

\section{RESULTS AND DISCUSSION}

Modified CHB-MLIs by artificial neural network technique is designed and simulated using the MATLAB/Simulink Software. Based on DC source. The simulations work has been carried out of a single phase of modified CHB-MLIs for value of switching frequency $2500 \mathrm{~Hz}$. The load used is single-phase with $20 \Omega$ and $5 \mathrm{mH}$. The DC capacitor voltage Vdc $=300 \mathrm{~V}$. In this simulation operation, the duration of time was equal to $0.02 \mathrm{sec}$ for each cycle. The value of $\mathrm{MI}=0.949$ was used and the switching angles were calculated and simulated which were equal to $\theta_{1}=11.54$ and $\theta_{2}=39.21$ at the switches of a single-phase modified CHB-MLIs of five levels. In Fig. 11 as can be observed of predicted data and original data for the THD with test values.

The training set is used for computing the gradient and updating the network weight and bias values. The validation set is used to monitor the error during training process in order to avoid overfitting. The test set is used to test the training performance training: $\mathrm{R}=0.99995$ as shown in Fig. 12.

The simulation model of output voltage waveform is as shown in Fig. 13 for timing diagram of optimisation

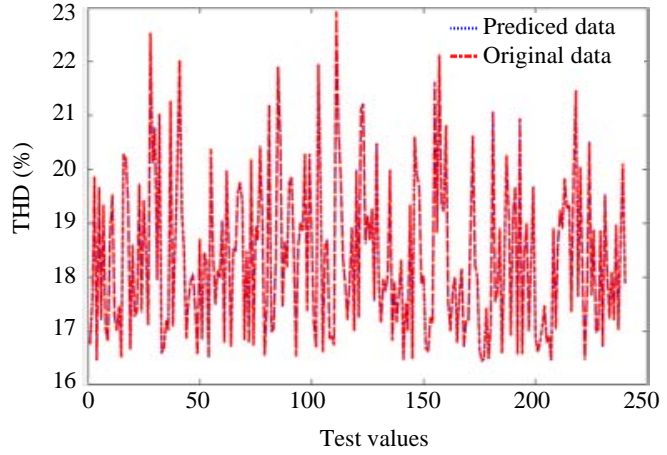

Fig. 11: Predicted data and original data for THD

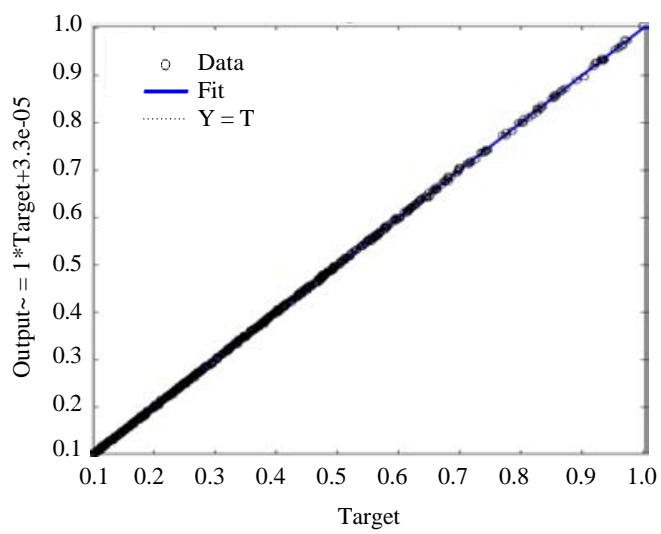

Fig. 12: Training performance angles for ANN (Training: $\mathrm{R}=0.99995)$

Table 2: Overall values of MI, switching angles and THD for voltage and current of modified CHB-MLI for five-levels based on proposal ANN and PSO techniques

\begin{tabular}{llllll}
\multicolumn{7}{c}{ ANN and PSO techniques } \\
\hline Five-level & MI & $\theta_{1}$ & $\theta_{2}$ & THD $_{\mathrm{V}}(\%)$ & THD $_{\mathrm{A}}(\%)$ \\
\hline PSO & 0.949 & 31.41 & 41.93 & 15.30 & 3.80 \\
Proposal ANN & 0.949 & 11.54 & 39.21 & 14.48 & 2.05 \\
\hline
\end{tabular}

ANN consist $\mathrm{S}_{1}, \mathrm{~S}_{2}, \mathrm{~S}_{3}, \mathrm{~S}_{4}$ and bi-directional $\mathrm{S}_{5}$ of modified CHB-MLIs of five levels. The optimisation of output voltage waveforms is based on the accurate calculation of switching angles obtained which are $\theta_{1}=11.54$ and $\theta_{2}=$ 39.21 with $\mathrm{MI}=0.949$ as shown in Fig. 14. Using the ANN technique, (Fig. 15) shows the harmonic spectrum of the optimisation of output voltage waveform of a modified CHB-MLIs of five levels with THD values equivalent to $14.3 \%$.

The simulation result of a single-phase modified CHB-MLI for the output voltage and current waveform using ANN. Figure 16 and 17 shows the harmonic spectrum of the ANN optimisation of output current waveform of a single-phase modified CHB-MLI with THD values equivalent to $0.9 \%$.

As shown in Table 2 overall values of MI, switching angles and THD for voltage of modified CHB-MLI for five-levels based on proposal ANN and PSO techniques. Figure 18 shows the MATLAB plotting output for 

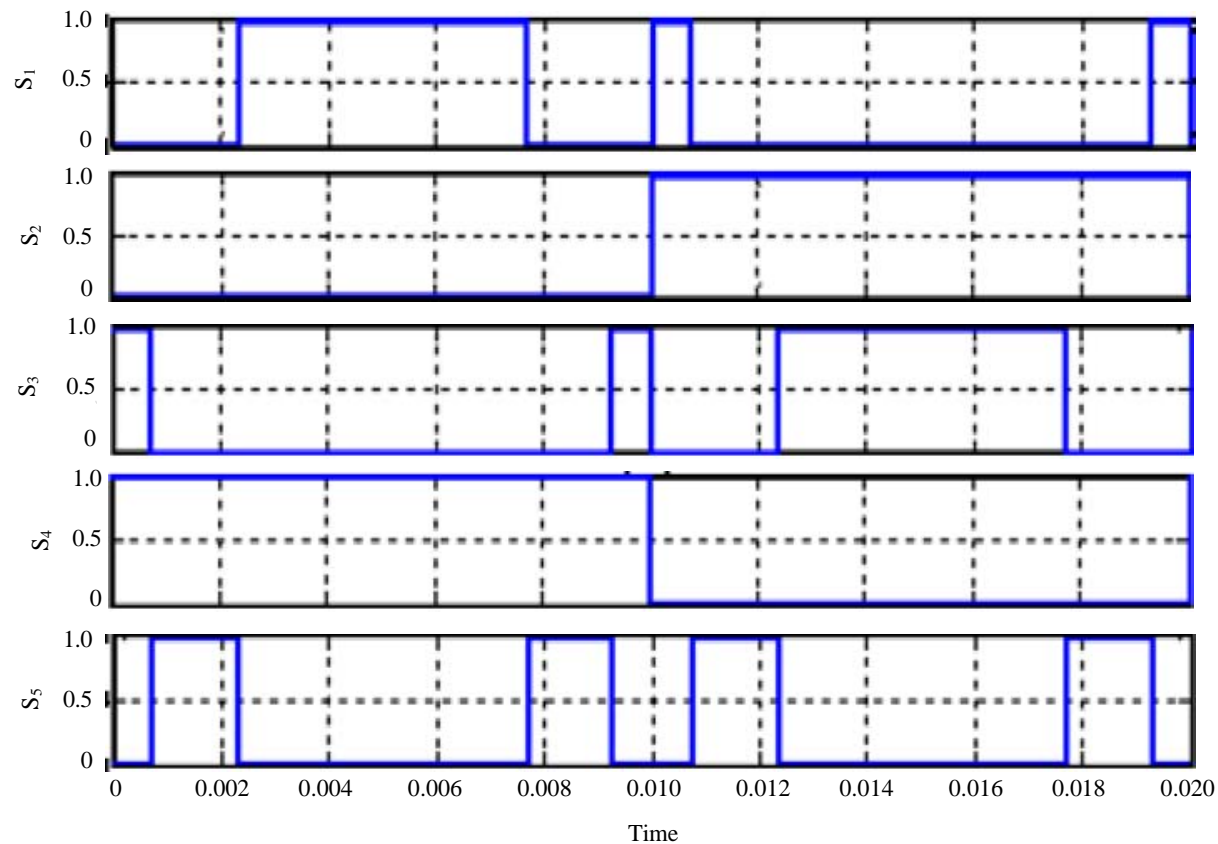

Fig. 13: Timing diagram for $\mathrm{S}_{1}, \mathrm{~S}_{2}, \mathrm{~S}_{3}, \mathrm{~S}_{4}$ and bi-directional $\mathrm{S}_{5}$ using $\mathrm{ANN}$ technique

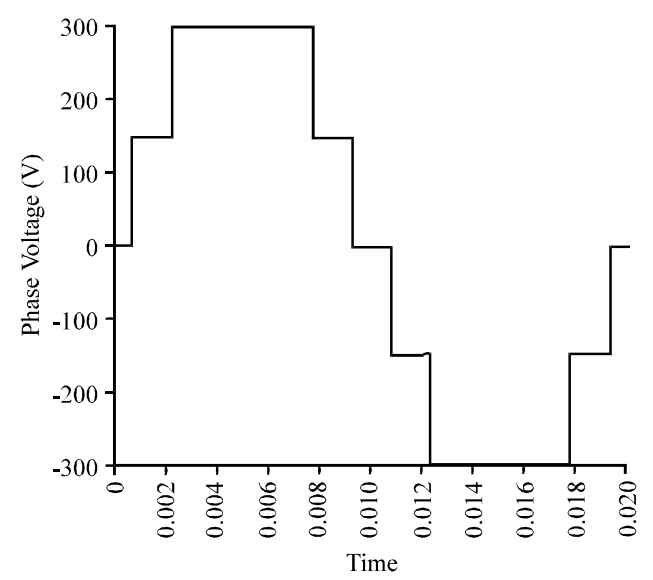

Fig. 14: Five-level output voltage using ANN technique

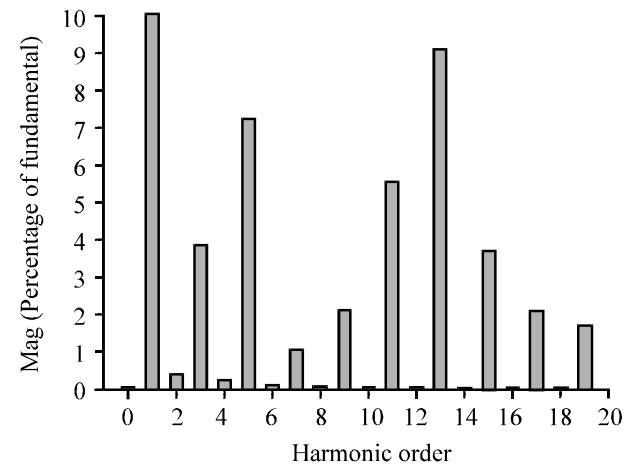

Fig. 15: Harmonic spectrum for output voltage waveform using ANN technique (Fundamental $(50 \mathrm{~Hz})=$ $318.1, \mathrm{THD}=14.48 \%$ )

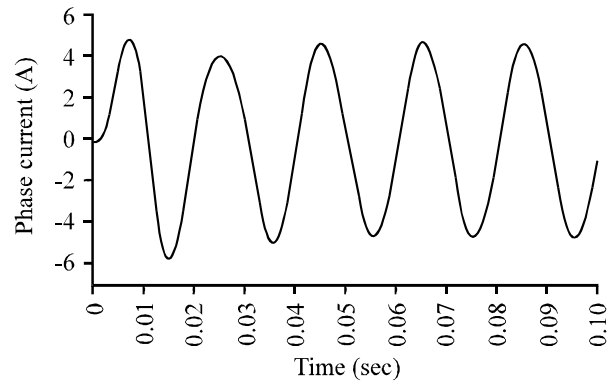

Fig. 16: Optimization harmonic spectrum of output voltage waveform using ANN technique

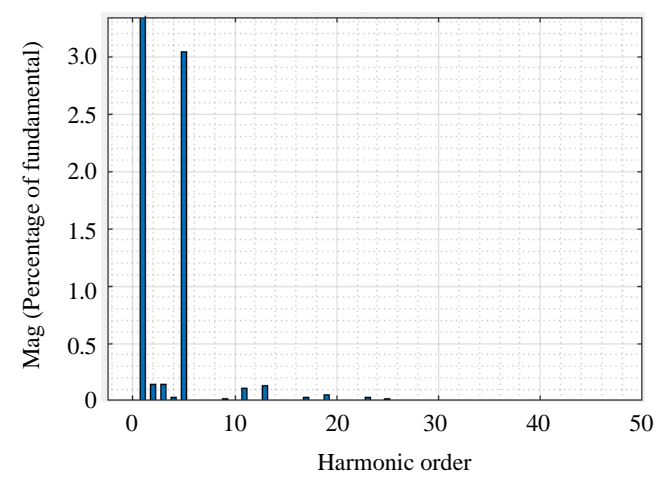

Fig. 17: Optimization harmonic spectrum of output current waveform using ANN technique (Fundamental $(50 \mathrm{~Hz})=2.913, \mathrm{THD}=2.05 \%)$

switching angles and the THD values for voltage and current based on proposal ANN and PSO techniques. 


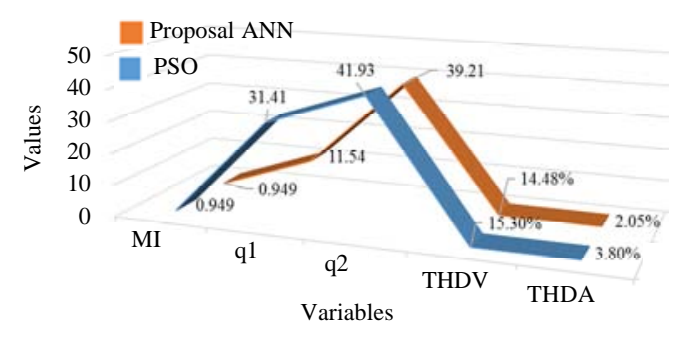

Fig. 18: Overall values of MI, versus the switching angles and the values of THD for voltage and current of modified CHB-MLI of five-levels based on proposal ANN and PSO techniques

\section{CONCLUSION}

The simulationresults showed that the higher level of inverter it will produce lower harmonics contents of the modified CHB-MLIs using the both techniques. The five-level M-CHBMI with ANN controller has been improve the output voltage and current performance and achieve a lower THD. However, ANN technique produces lower content of THD of the modified CHB-MLIs output voltage and current waveform compared to $\mathrm{PSO}$ technique due to switching angles of the ANN technique is simple and efficient.

\section{ACKNOWLEDGEMENT}

This research is sponsored by the grant Penyelidikan Jangka Pendek (PJP) which the number is PJP/2019/ FKE(2A)/S01668. The researchers would also like to thank the Centre for Research and Innovation Management Universiti Teknikal Malaysia Melaka (CRIM-UTeM) for the funding to support this project to providing the facilities and research environment.

\section{REFERENCES}

Ahmed, R.A., S. Mekhilef and H.W. Ping, 2010. New multilevel inverter topology with minimum number of switches. Proceedigs of the TENCON 2010-2010 IEEE Region 10 Conference, November 21-24, 2010, IEEE, Fukuoka, Japan, ISBN:978-1-4244-6889-8, pp: 1862-1867.

Bodo, N., E. Levi and M. Jones, 2012. Investigation of carrier-based PWM techniques for a five-phase open-end winding drive topology. IEEE. Trans. Ind. Electron., 60: 2054-2065.

Colak, I., E. Kabalci, 2013. Developing a Novel Sinusoidal Pulse Width Modulation (SPWM) Technique to Eliminate Side Band Harmonics. Int. J. Electr. Power Energy Syst., 44: 861-871.
Demirdelen, T., R.I. Kayaalp and M. Tumay, 2017. Simulation modelling and analysis of modular cascaded multilevel converter based shunt hybrid active power filter for large scale photovoltaic system interconnection. Simul. Modell. Pract. Theor., 71: $27-44$.

Hosseini, S.H., M. Ahmadi and S.G. Zadeh, 2011. Reducing the output harmonics of cascaded H-bridge multilevel inverter for electric vehicle applications. Proceedings of the 8th International Conference on Electrical Engineering/Electronics, Computer, Telecommunications and Information Technology (ECTI) Association of Thailand, May 17-19, 2011, IEEE, Khon Kaen, Thailand, ISBN: 978-1-4577-0425-3, pp: 752-755.

Nedumgatt, J.J., D.V. Kumar, A. Kirubakaran and S. Umashankar, 2012. A multilevel inverter with reduced number of switches. Proceedings of the 2012 IEEE Students Conference on Electrical, Electronics and Computer Science, March 1-2, 2012, IEEE, Bhopal, India, ISBN:978-1 -4673-1516-6, pp: 1-4.

Omar, R., M. Rasheed, N. Mies, M. Sulaiman and W.A. Halim, 2019. The Performance of the Modified Cascaded H-Bridge Multilevel Inverters (CHB MLIS) with Various Modulation Index (MI) Using Firefly Algorithm. In: Advances in Engineering Technology, Singh, J. (Ed.). AkiNik Publications, Delhi, India, pp: 127-155.

Parkash, A., S.L. Shimi and S. Chatterji, 2014. Harmonics reduction in cascade H-bridge multilevel inverters using GA and PSO. Intl. J. Eng. Trends Technol., 12: 453-465.

Rasheed, M., R. Omar, M. Sulaiman and W.A. Halim, 2019. Particle Swarm Optimisation (PSO) algorithm with reduced number of switches in MultiLevel Inverter (MLI). Indonesian J. Electr. Eng. Comput. Sci., 14: 1114-1124.

Rasheed, M., R. Omar, Nizam and M. Sulaiman, 2018. Optimization switching angle based on Practical Swarm Optimization (PSO) of A DSP-TMS320F 2812 controlled for multilevel inverter. Intl. J. Eng. Technol., 7: 5666-5672.

Reddy, V.N.B., V. Narasimhulu and S. Babu, 2010. Control of cascaded multilevel inverter by using carrier based PWM technique and implemented to induction motor drive. Intl. J. Autom. Control Syst. Eng., 10: 11-18.

Rodriguez, J., S. Bernet, B. Wu, J.O. Pontt and S. Kouro, 2007. Multilevel voltage-source-converter topologies for industrial medium-voltage drives. Ind. Electron. IEEE. Trans., 54: 2930-2945.

Salleh, S., M.F. Rahmat, S.M. Othman and K.A. Danapalasingam, 2011. Review on modeling and controller design in pneumatic actuator control system. Intl. J. Smart Sens. Intell. Syst., 8: 338-367. 
Subramanian, D. and R. Rasheed, 2013. Nine-level cascaded H-bridge multilevel inverter. Intl. J. Eng. Innovative Technol., 3: 201-205.

Tipsuwanporn, V., W. Sawaengsinkasikit, A. Numsomran and K. somsamai, 2011. 3 Phase induction motor controlled with 9-level diode-clamp inverter. Proceedings of the World Congress on Engineering and Computer Science Vol. 1, October 19-21, 2011, San Francisco, California, USA., ISBN: 978-988-18210-9-6, pp: 1-5.

Vijayakumar, R., A. Natchiappan, C. Devilalitha and R. Mazhuventhi, 2015. Selective harmonic elimination PWM method using seven level inverters by genetic algorithm optimization technique. Intl. J. Eng. Res. Technol., 4: 812-818.
Xiao, B., K. Shen, J. Mei and L.M. Tolbert, 2012. Control of cascaded H-bridge multilevel inverter with individual MPPT for grid-connected photovoltaic generators. Proceedings of the 2012 IEEE International Conference on Energy Conversion Congress and Exposition (ECCE), September 15-20, 2012, IEEE, Raleigh, North Carolina, ISBN: 978-1-4673-0802-1, pp: 3715-3721.

Zhang, L., 2017. Design and implementation of neural network based chaotic system model for the dynamical control of brain stimulation. Proceedings of the 2nd International Conference on Neuroscience and Cognitive Brain Information (BRAININFO 2017), July 23-27, 2017, Nice, France, ISBN: 978-1-61 208-579-1, pp: 14-21. 